\title{
VALORES EPISTÉMICOS Y JUSTIFICACIÓN: RAZÓN TEÓRICA Y RACIONALIDAD PRÁCTICA EN L. WITTGENSTEIN (SOBRE LA CERTEZA)
}

\author{
Cristina CORREDOR \\ Universidad de Valladolid
}

Un estudio del concepto wittgensteiniano de sistema de argumentación, tal y como éste aparece reflejado y puede reconstruirse en Sobre la Certeza, permite determinar en qué medida puede hablarse, para los sistemas de argumentación empíricos -y siempre según la caracterización de Wittgenstein-, de una estructura de reglas universales, o es inevitable concluir el particularismo y la naturaleza contingente del concepto.

En la obra indicada, Wittgenstein había estudiado críticamente la tesis de Moore según la cual existen enunciados que expresan certezas básicas y cuya naturaleza es tal que su verdad se establecería con una suerte de evidencia "a priori». Sin hacerlo explícito, Wittgenstein centra su atención -al igual que Moore- en el uso epistémico, o semántico-cognoscitivo, del lenguaje; e.d., en el uso que los hablantes hacen de éste para presentar posibles estados de cosas y representar hechos del mundo objetivo y, en particular, para formular teorías científicas. El análisis y la reconstrucción de los diversos modos de empleo de los enunciados señalados por Moore llevan a Wittgenstein a concluir que, efectivamente, a la base de las representacions cognoscitivas se encuentran determinados enunciados a los que los hablantes asignan el valor de, por así llamarlos, "certezas paradigmáticas", y que, como tales, no pueden ponerse en cuestión de manera coherente. Pero, en contra de Moore, Wittgenstein no considera que a estas certezas paradigmáticas pueda atribuírseles el valor de verdades a priori. Se trata, más bien, de algo a lo que se llega por un proceso de análisis y que sólo cabe «constatar" y "describir»; se sitúan en el trasfondo 
irrebasable de lo que constiye una forma de vida (cf. Sobre la Certeza, $\$ \$ 94$, 204-205, 358-359).

El concepto de sistema de argumentacion, según puede reconstruirse a partir del estudio de los diversos modos en que Wittgenstein lo utiliza, permite afirmar que Wittgenstein desarrolla, en diversos momentos, un tipo de reflexión casi-transcendental. Ello le permite identificar elementos pragmático-formales, procedimentales y generales de contexto, que estarían presentes en, y serían constitutivos de la validez de, nuestras representaciones científicas del mundo. Entre estos elementos normativos se encontrarían: el presupuesto de objetividad en el uso epistémico del lenguaje (cf. \$\$14-16, 175-180, 308, 336); la exigencia de reconocimiento intersubjetivo (cf. \$\$18, 243-245, 270-271, 438, 449, 450, 484, 648); la posibilidad de duda y de crítica, y la posibilidad ligada a ellas de justificación racional, internamente conectada con la falibilidad del conocimiento (cf. $\$ \$ 262,612,648,669$; tb. $\$ \$ 341,342,625$ ); una forma de lo que podría considerarse el principio de expresividad aplicado al uso epistémico del lenguaje (cf. \$349) e incluso, dando un paso más, la posibilidad de reconstruir explícitamente el sistema de reglas subyacente a la práctica epistémica (cf. $\$ 152)$; el valor de la noción de verdad como presupuesto regulativo en un sentido casi-kantiano (cf. $\$ \$ 403,404,415$, si bien en otros puntos parece defender una concepción sustantiva o material); y finalmente, no como una condición constitutiva - como en todos los casos anteriores- pero sí como un criterio, el de la validez intersubjetiva del significado de los conceptos de la ciencia (cf. \$\$369, 456).

A lo que se querría prestar atención ahora es a lo siguiente. En repetidas ocasiones, al intentar aclarar en qué se basa la peculiar «evidencia» que los hablantes aceptan de modo tácito para determinados enunciados, y que justificaría su valor de certezas paradigmáticas para la formulación de teorías científicas, Wittgenstein apela explícitamente a situaciones en las cuales un juez o un tribunal civil habrían de emitir un juicio (cf. $\$ \$ 115,117,321,335,441,485,500$, $557,604,607)$. Esta figura entra en juego, en el curso de la discusión, de dos maneras fundamentalmente. En ocasiones se trata de un símil: se compara tácitamente la actividad de dirimir argumentativamente la validez epistémica de cualesquiera enunciados, y en particular los que expresan certezas paradigmáticas, con el tipo de procedimiento por el cual en un tribunal de justicia, $o$ ante un juez en el transcurso de un juicio, se pretende determinar si una declaración o una testificación pueden considerarse (representación verdadera de) un hecho, que pasará a constituirse en hecho probado $(\$ \$ 485,557)$. En otras oca- 
siones cabe suponer que el tribunal está compuesto por los propios hablantes, eventualmente por especialistas en la materia de que se trate, y son sus argumentos y sus razones los que permiten considerar justificada la validez epistémica de los enunciados (\$604). Puede considerarse que Wittgenstein emplea de dos modos la referencia a un juicio, en relación con enunciados de valor epistémico. En primer lugar, para aclarar la función que dichos enunciados podrían cumplir en tanto que justificación o fundamentación final de cuestiones de hecho ante el tribunal o el juez (\$604). En segundo lugar, para reflexionar sobre el modo en que un enunciado podría ver su valor epistémico «sometido a juicion, y la forma en que esta validez podría cuestionarse o justificarse, esto es, considerarse «suficientemente probada» (cf. $\$ \$ 599,600$ ).

Lo primero parece requerir el conceder a la noción de verdad - de lo aceptado como científicamente probado- un "algo más» respecto a la noción de justificación racional —es decir, de lo que el juez, y con él Wittgenstein, sitúan "más allá de toda duda razonable» (\$607) - Wittgenstein constata, sin embargo, que el establecimiento de esa validez epistémica depende también de que se satisfagan determinadas condiciones generales de contexto y protocolarias como "que estemos en situación de conocer" (\$555)—. Otras veces, sin embargo, no parece posible trazar una delimitación precisa entre lo que es válido y lo que no: todo depende de haberse situado en el contexto de un juego de lenguaje (cf. e.g. $\$ \$ 604,609,620$ ). Si se quisiera identificar el «limite casi-trascendental" del conocimiento, éste lo constituiría el propio juego de lenguaje epistémico: es éste el que aporta los criterios para ese «algo más», con respecto al cual "la fundamentación halla un fin» (\$563).

La conclusión parece ser: que hay criterios objetivos para justificar la validez epistémica de un enunciado y del uso semántico-cognoscitivo del lenguaje en general (cf. $\$ 488$, final); pero éstos sólo pueden conocerse y aplicarse en un marco de juegos de lenguaje, fuera del cual no puede hablarse de "verdadero" o "falso", sino de "sinsentido" o de falta de comprensión o de entendimiento de los hablantes, es decir, de desconocimiento del juego de lenguaje $(\$ \$ 315,497$, 609).

\section{II}

Para "quebrar» el contextualismo que parece seguirse haría falta preguntarse por las condiciones de posibilidad y de validez que son constitutivas de los jue- 
gos de lenguaje, y que se presentan con un carácter necesario y máximamente general. Entre estas condiciones se contarían las que hacen referencia al surgimiento de los juegos de lenguaje y a su ampliación o transformación (e.g. $\$ \$ 497,494,628 ; \$ 568)$, o al presupuesto pragmático de una realidad extra-lingüística $(\$ \$ 575,617)$. Pero este tipo de investigación requiere que se muestre, previamente, su plausibilidad; es decir, es preciso identificar y justificar suficientemente el lugar de la "apercepción casi-trascendental" que hace posible recuperar reflexivamente esas condiciones constitutivas. Y éste ha de ser, por tanto, el primer aspecto a estudiar aquí.

Podría considerarse que, en determinados momentos de su discusión, Wittgenstein introduce esta perspectiva reflexiva. Lo hace cuando, de modo explícito $o$ a veces tácito, tiene que referirse al juego de lenguaje que haría posible describir los juegos de lenguaje en cuanto tales. De hecho, se ha considerado que es este tipo de descripción lo que define el «método wittgensteiniano». En las Investigaciones filosoficas Wittgenstein no se propone estudiar lo que habitualmente se consideran procesos o estados mentales, o si los hay o no; tampoco pretende probar tesis empíricas relativas a la naturaleza de la sensibilidad, la percepción o el pensamiento. La investigación se centra en algunos conceptos paradigmáticos; y es importante recordar que todos los conceptos son, bajo las premisas de las Investigaciones, conceptos lingüísticos. El método consiste en seleccionar situaciones arquetípicas de aplicación de los mismos y en aclarar los modos en que el concepto se emplea en esas situaciones, es decir, con qué fines, o en el contexto de qué actividades o comportamientos. Éste es el estudio que Wittgenstein lleva a cabo con el concepto de ladrillo, y también con los conceptos de comprensión, significado o intención. La dificultad con los tres últimos nace de su carácter de conceptos "de segundo orden", por decirlo así; son conceptos que se aplican a otros conceptos lingüísticos, es decir, a la propia actividad del lenguaje en cuanto tal. Así, mientras el concepto de ladrillo, y otros conceptos empíricos similares, pueden quedar aclarados señalando un ámbito de actividad y alguna práctica arquetípica de carácter extra-lingüístico, en el caso de conceptos como significado o comprensión es preciso tomar en consideración actividades normativas, en cuyo contexto se pretende explicar, justificar o reconstruir otros usos del lenguaje. Esto es en parte lo que presta a la reflexión su carácter a veces paradojico y su dificultad.

Lo anterior no se ve facilitado por la presunción de Wittgenstein de que su método es "descriptivo", o por sus reiteradas exhortaciones a "mirar lo que está a la vistam. La elección de determinadas situaciones de habla como contextos 
de uso arquetípicos, así como la construcción de otros más simples, virtuales o ficticios, a los que Wittgenstein da el valor de juegos de lenguaje-modelo, permite sin embargo poner en evidencia que se trata, más que de una descripción en sentido estricto, de una reflexión que se lleva a cabo en actitud reconstructiva. Y es este mismo método analítico-reconstructivo el que está entrando en juego en Sobre la Certeza, aquí aplicado a los conceptos de conocimiento o saber. La identificación de situaciones arquetípicas, así como la construcción de contextos virtuales y de casos simplificados de aplicación de esos conceptos, muestra que todos ellos se integran en el marco de una actividad normativa que evalúa, aclara o justifica lo que constituye una representación o descripción válidas de la realidad. Se trata aquí también, como en las Investigaciones, de conceptos «de segundo orden" que se aplican a otras elaboraciones enunciativas - a fortiori lingüísticas - con la pretensión de determinar su validez.

Como primer elemento constitutivo del uso de los conceptos epistémicos de conocimiento o saber aparece uno ya señalado: el requisito implícito de que el hablante, ante un interlocutor que así lo requiera, pueda justificar con razones, argumentando, lo que ha enunciado. Wittgenstein vincula además esta condición con otra analíticamente previa: que hablante e interlocutor posean un conocimiento compartido del juego de lenguaje de que se trate. $\mathrm{Y}$, con ello, parece moverse en un círculo, en una especie de "clausura pragmática»: pues qué vale como comprobación suficiente para un enunciado, es algo que "pertenece a la descripción del juego de lenguaje» (cf. $\$ \$ 18,80,91,110,128,129$ ); y esta misma descripción del juego de lenguaje, como la llevada a cabo por Wittgenstein, tiene lugar mediante enunciados, que pretenden a su vez comprobación o justificación suficiente.

\section{III}

Podría interpretarse que es el intento de romper este aparente círculo pragmático lo que lleva a Wittgenstein a introducir un elemento nuevo y que, sin conciencia del problema indicado, puede parecer espúrio o fuera de contexto, es decir: fuera del ámbito de la práctica epistémica del conocimiento y de la ciencia. Pero es precisamente esta salida del contexto estrictamente epistémico lo que le permite adoptar un punto de vista reflexivo y hacer explícitos los presupuestos normativos que constituyen la actividad epistémica en cuanto tal. El nuevo elemento, ya señalado, es el de un contexto práctico: el de un juicio an- 
te un tribunal o un juez, en cuyo transcurso desempeña un papel el examen de determinadas oraciones enunciativas, descriptivas de hechos o relativas a cuestiones de hecho. Se han visto ya los dos modos en que este recurso entra en juego. Pero falta un análisis que muestre su alcance: en qué medida la investigación de Wittgenstein encuentra aquí el punto de la «apercepción casi-trascendental» que se buscaba y qué conclusión cabe extraer respecto a su propuesta filosófica.

Así, la referencia al procedimiento en la sala del juicio le permite observar que, cuando se trata de establecer una cuestión de hecho sometida a examen, en ocasiones son las circunstancias las que prestan a la aseveración enunciativa del hecho una determinada probabilidad (\$335). Esto puede interpretarse como la exigencia, que se convierte en criterio epistémico de validez, de una consistencia entre la enunciación de hechos constatados - los que constituyen las "circunstancias conocidas" - y el enunciado sometido a examen. Esta exigencia de consistencia se sitúa a su vez en el marco de un sistema de argumentación $(\$ \$ 105,124)$ y descansa sobre una noción de racionalidad que lleva consigo la aceptación de ciertos enunciados que, en tanto que fundamentos «de todo preguntar y de todo pensamiento" ( $\$ 415)$, se consideran "más alla de toda duda razonable» (\$416). Todos los que toman parte en el juicio han de compartir estos presupuestos.

La situación del juicio permite discriminar, como Wittgenstein hace explícito, entre la mera certeza subjetiva y criterios de validez públicamente reconocidos y constatables, como el de que se den circustancias de contexto adecuadas para el conocimiento del virtual estado de cosas $(\$ \$ 441,557)$, o el de que sea posible justificar ante los demás aquello que se ha afirmado (\$485). Pero la situación del juicio introduce, al mismo tiempo, la dificultad de remitir, como condición constitutiva inevitable, al trasfondo irrebasable y ya siempre dado de una forma de vida $(\$ \$ 94,110,128,129)$. No obstante, en otros momentos Wittgenstein parece rechazar el carácter inevitablemente relativista de esa remisión.

Podría concluirse que lo que la incorporación de ese contexto práctico, el de un juicio, ha aportado, es de doble alcance. En primer lugar, remite determinados enunciados de valor epistémico paradigmático — como «el agua hierve a $100^{\circ} \mathrm{C} \rightsquigarrow$, o que expresan principios y leyes fundamentales - como el principio de inducción - a un contexto de actividad normativa: a aquel contexto en el cual se "somete a juicio", a revisión crítica o a justificación, la validez episté- 
mica tácitamente aceptada. En segundo lugar, se muestra que este tipo de reflexión tiene lugar mediante un procedimiento argumentativo, del cual son constitutivos a su vez determinados presupuestos normativos -como las exigencias de consistencia lógica y adecuación a la experiencia previa, y de exposición y reconocimiento público de los argumentos-y es constitutiva asimismo una concepción implícita de la racionalidad. Pero, de nuevo, la aproximación que Wittgenstein lleva a efecto en algunos puntos de la noción de verdad a la de justificación racional (cf. p. e. \$607) no impide la conclusión a la que finalmente parece verse llevado: la de que la última justificación sólo puede hallarse en una foma de actividad y de práctica únicamente susceptibles de constatación y descripción.

Ahora bien: en el contexto de un juicio, el procedimiento práctico de justificación ha sido explícitamente establecido y sancionado normativamente, y los presupuestos a que se ha hecho referencia, y que subyacen a la práctica discursiva de la argumentación racional, tienen un carácter no sólo constitutivo -no son sólo "cuestiones de hecho", en el sentido de que han de encontrarse operativos y verse suficientemente respetados por los participantes-, sino que adquieren también un valor regulativo; esto último no sólo porque puedan ser explícitamente invocados como criterios evaluativos. Son presupuestos regulativos también en el sentido casi-kantiano de que orientan la actividad hacia un ideal que, aunque se reconozca de hecho irrealizable, es el fin último del procedimiento fáctico. Este valor de presupuesto normativo (regulativo) es el que cabe reconocer, por ejemplo, en la noción de verdad, cuando Wittgenstein reflexiona sobre ello. Así: «El juez podría, efectivamente, decir: 'Esta es la verdad, en la medida en que un ser humano puede conocerla' (...)" (\$607; curs. mías, C.C.). $Y$, aunque se pregunta a sí mismo con escepticismo qué añade la última valoración del juez, una última precisión del propio Wittgenstein incorpora tácitamente el valor regulativo de esa valoración añadida: pues muestra que se acepta como verdadero, provisionalmente, lo que en un estadio dado del conocimiento cabe situar "más allá de toda duda razonable".

Pero, también, de nuevo una vez más: a la aceptación de la falibilidad del conocimiento, como presupuesto constitutivo y regulativo, se une la conciencia de la falibilidad de decisiones prácticas situadas en un contexto, aun cuando éstas se ajusten formalmente a los requisitos normativos sancionados. Sólo es posible dar cuenta de esta "falibilidad práctica" considerando los presupuestos constitutivos de la propia racionalidad práctica, al mismo tiempo, «ideales regulativos" en un sentido kantiano. 


\section{IV}

Yendo más allá del propio Wittgenstein, cabe observar el tipo de «salto" conceptual que su reflexión ha dado aquí: del ámbito de la descripción analítica - de cuáles son las representaciones epistémicamente válidas- al ámbito de la justificación normativa - del en qué se fundamenta, o cómo se justifica, esa validez-. Por tanto: de la razón teórica, a la razón pura práctica. Es decir, es el procedimiento argumentativo, según ciertas reglas, el que constituye -y no sólo evalúa - la validez epistémica de los enunciados. Al apelar, en el curso de una reflexión que parte de la teoría del conocimiento, a un tribunal civil de argumentación, Wittgenstein está subordinando el ámbito epistémico de la formulación de teorías al ámbito práctico de su justificación normativa; y, con ello, de la teoría de la ciencia a la filosofía práctica.

Pero la cuestión que, en última instancia, se querría plantear es la de en qué medida el movimiento anterior de Wittgenstein permitiría defender la universalidad - por el carácter procedimental conforme a ciertas reglas- de los procesos discursivos de justificación. El problema es que no basta con situarse en el plano pragmático-formal, de iure, de justificación, para reconocerles este carácter máximamente general o universal. Es preciso que sean reglas procedimentales también las reglas "de segundo orden», es decir: aquéllas que permitirían reconstruir y justificar la validez de los propios procesos discursivos de argumentación racional. Como se ha venido constatando, por sus propias declaraciones parecería que, para Wittgenstein, aquí es donde «se ha tocado fondon. La diferencia categorial que se ha indicado entraría en correspondencia con la que, en el marco del sistema conceptual kantiano, cabría establecer en relación con el esquematismo trascencental de los conceptos puros del entendimiento. Este esquematismo es el que asegura la aplicabilidad de esos conceptos a los fenómenos; Kant lo entiende como una regla para la determinación de nuestra intuición sensible conforme a ciertos conceptos generales (cf. Critica de la razón pura, B180). Pero Kant no llegó a distinguir entre un esquematismo de conceptos "de primer orden", es decir: el disponer de un esquema o regla de acción que se manifiesta en la aplicación de los conceptos a los fenómenos, y un esquematismo de conceptos "de segundo orden", es decir: el disponer de un esquema o regla que permita la conexión formal de esquemas de acción de primer orden (p.e., el principio de causalidad). Estas reglas «de segundo orden" serían, en el marco de la investigación de Wittgenstein, reglas procedimentales de argumentación racional, del tipo de las que entran en juego en la discusión ar- 
gumentativa de un tribunal civil. Tendría que tratarse, por tanto, de reglas puramente formales y procedimentales, y que operasen con las reglas o esquemas de acción de "primer orden" -éstas, en principio, inseparables de sus realizaciones empíricas, de acuerdo con la noción witgensteiniana de seguir-unaregla - permitiendo su reconstrucción, o formulación explícita, y la discusión sobre ellas. Esta posibilidad de un ascenso pragmático-procedimental es la que Wittgenstein parece haber rechazado.

$\mathrm{Y}$, sin embargo, cabría preguntarse por el tipo de procedimiento que subyace a su propio análisis y reconstrucción, tal y como se lleva a cabo en Sobre la certeza, y que subyace igualmente al tipo de "descripción última» a la que él mismo apela y para la que Wittgenstein tácitamente pretende una validez que trasciende contingencias o particularismos de contexto. Vuelve a presentarse, así, el tipo de paradoja que Wittgenstein sí identificó, en el plano semántico del lenguaje, en el Tractatus. Y cabe preguntarse si no es igualmente posible identificar, en el ámbito de iure de la argumentación racional, el tipo de reglas casitrascendentales que permitirían salvar la paradoja pragmática y defender la plausibilidad del carácter universal de estas reglas.

En la medida en que el contexto práctico del juicio representa ese punto de "apercepción casi-trascendental" desde el que se hace posible una recuperación reflexiva y una reconstrucción de las condiciones de posibilidad y de validez de la descripción válida de la experiencia, Wittgenstein puede justificar la validez que él pretende para su propia "descripción» de los juegos de lenguaje. Pero, al mismo tiempo, sería preciso reconocer, en ese ámbito práctico de argumentación racional que representa el juicio, el lugar de un juego de lenguaje cuyas condiciones constitutivas y presupuestos normativos -es decir, regulativoses inseparable de, y acompaña siempre a, el entramado fáctico de juegos de lenguaje en su conjunto - subyaciéndoles y permitiendo su reconstrucción explícita en el ámbito práctico de actividades normativas.

\section{Bibliografía}

Kant, I. (1781, 1787): Kritik der reinen Vernunft, Meiner, Hamburgo.

WittgensteIn, L. (1933): Tractatus Logico-Philosophicus, en Werkausgabe, Suhrkamp, Frankfurt, vol. 1.

- (1953): Philosophische Untersuchungem en ibid, vol. 1.

- (1969): Über Gewissheit, en ibid., vol. 8. 